Harrison, C. S. (1971) Dysplasia epiphysealis capitis femoris. Clinical Orthopaedics and Related Research, 80, 118-125.

Harrison, M. H. M., Turner, M. H., and Jacobs, P. (1976) Skeletal immaturity in Perthes' disease. Journal of Bone and Joint Surgery, 58-B, 37-40

Lauritzen, J. (1974) The arterial supply to the femoral head in children. Acta Orthopaedica Scandinavica, 45, 724-736.

Lauritzen, J. (1975) Legg-Calvé-Perthes disease. A comparative study. Acta Orthopaedica Scandinavica, Supplement 159.

Legg, A. (1910) An obscure affection of the hip-joint. Boston Medical and Surgical Journal, 162, 202-204.

Matsoukas, J. A. (1975) Viral antibody titers to rubella in coxa plana or Perthes' disease. Perthes' disease: is it the late osseous residua of a minor prenatal rubella? Acta Orthopaedica Scandinavica, 46, 957-962.

Meyer, J. (1964) Dysplasia epiphysealis capitis femoris. A clinical-radiological syndrome and its relationship to Legg-Calvé-Perthes disease. Acta Orthopaedica Scandinavica, 34, 183-197.

Nevelös, A. B., Colton, C. L., and Burch, P. R. J. (1977) Congenital hip dysplasia without dislocation. Personal communication.

Pasquié, M. (1970) L'ostéochondrite primitive de la hanche. Introduction. I, Étiologie. Revue de chirurgie orthopédique et réparatrice de l'appareil moteur, 56, 588-593.

Pedersen, E. K. (1960) Dysplasia epiphysialis capitis femoris. Journal of Bone and Joint Surgery, 42-B, 663.

Salter, R. B., Kostuik, J., and Dallas, S. (1969) Avascular necrosis of the femoral head as a complication of treatment for congenital dislocation of the hip in young children: a clinical and experimental investigation. Canadian Journal of Surgery, 12, 44-61.

Soeur, R., and de Racker, Ch. (1952) L'aspect anatomopathologique de l'ostéochondrite et les théories pathogéniques qui s'y rapportent. Acta Orthopaedica Belgica, 18, 57-102.

Somerville, E. W. (1971) Perthes' disease of the hip. Journal of Bone and Joint Surgery, 53-B, 639-649.

Stainsby, G. D., and Quibell, E. P. (1967) Perthes-like changes in the hips of children with thalidomide deformities. Lancet, 2, $242-243$.

Tönnis, D. (1976) Normal values of the hip joint for the evaluation of $\mathbf{x}$-rays in children and adults. Clinical Orthopaedics and Related Research, $119,39-47$.

Wilk, L. H. (1965) Juvenile osteochondrosis of the hip. Critical evaluation of pathogenesis and treatment. Journal of the American Medical Association, 192, 939-946.

Wilkinson, J., and Carter, C. (1960) Congenital dislocation of the hip. The results of conservative treatment. Journal of Bone and Joint Surgery, 42-B, $669-688$.

Wynne-Davies, R. (1970) Acetabular dysplasia and familial joint laxity: two etiological factors in congenital dislocation of the hip. A review of 589 patients and their families. Journal of Bone and Joint Surgery, 52-B, 704-716.

\title{
SPINAL DEFORMITIES IN MYELOMENINGOCELE
}

Those of us interested in spinal deformities have seen in recent years a new group of complex problems which develop in survivors with myelomeningocele. The deformities seen are scoliosis or kyphosis, both common, both severe. Not unrelated are the extraordinary deformities now also being seen in patients who have had theco-peritoneal shunts for hydrocephalus; in them scoliosis and lordosis are the particular problems.

The myelomeningocele patients who develop kyphosis are usually paraplegic, as are some of those with scoliosis. As the deformity progresses the child “jack-knifes", thus obstructing diaphragmatic movements and respiration. The kyphosis enlarges backwards to simulate Mr Punch's sternal prominence! The skin over this hump is anaesthetic, and sitting and lying soon produce intractable pressure sores. The child cannot lie, sit, walk and hardly breathe.

Malcolm Menelaus in this issue* describes his experience in Melbourne with some of these problems. Operative correction is essential, for a brace not only does not hold the deformity but the anaesthetic skin over the pelvis makes its use precarious. By the time these patients come to us their deformity is usually rigid and the anterior soft tissues contracted and inelastic. Excision of vertebrae is essential to obtain correction. His method of fixation after this presents some *Page 40. difficulties and may prove inadequate. In recent years we and others have divided the useless cauda equina, isolated the lumbar vertebral column, resected the necessary number of vertebrae and then applied a Dwyer cable from the posterior aspect, an operation which is not technically very taxing.

When to correct the kyphosis remains uncertain. Sharrard's pioneer operation was done early (Sharrard and Drennan 1972); Menelaus intervenes later. Nonunion and recurrence have complicated early intervention. With an ability to correct this deformity almost completely there may be advantages in waiting until at least the tenth year.

Because these problems are new there is little known or written of the natural history of these deformities. It would appear, however, that in the paraplegic infant with a kyphosis of twenty to thirty degrees, progression to a grotesque hunchback is inevitable. We urgently need a sound knowledge of the natural progression of all these deformities in myelomeningocele.

Although for the next decade orthopaedic surgeons will have a spate of these difficult problems, there is a prospect that their number will diminish. Selection at birth of babies with myelomeningocele suitable for closure is now more rigorous. The quality of life for the survivors has been ignored until recently, in part because of the difficulty of establishing the prognosis at 
birth. Even more hopeful is the work by Brock. He has shown that in mothers who have had one myelomeningocele baby, a foetus with an open spinal cord in a further pregnancy can be detected by finding high levels of fetoprotein in the amniotic fluid (Brock and Sutcliffe 1972). Termination of the pregnancy is then advisable. Even more helpful in prophylaxis is the more recent report (U.K. Collaborative Study 1977) which shows that blood levels of fetoprotein can be used as a preliminary screening for all mothers to identify those requiring confirmatory amniocentesis.

Professor J. I. P. James, M.S., F.R.C.S., University Department of Orthopaedic Surgery, Clinical Research Unit, Princess Margaret Rose Orthopaedic Hospital, Fairmilehead, Edinburgh EH10 7ED, Scotland.

\section{REFERENCES}

Brock, D. J. H., and Sutcliffe, R. G. (1972) Alpha-fetoprotein in the antenatal diagnosis of anencephaly and spina bifida. Lancet, 2, 197-199. Sharrard, W. J. W., and Drennan, J. C. (1972) Osteotomy-excision of the spine for lumbar kyphosis in older children with myelomeningocele. Journal of Bone and Joint Surgery, 54-B, 50-60.

U.K. Collaborative Study on Alpha-fetoprotein in Relation to Neural Tube Defects (1977) Maternal serum-alpha-fetoprotein measurement in antenatal screening for anencephaly and spina bifida in early pregnancy. Lancet, 1, 1323-1332.

\section{INSTABILITY OF THE KNEE JOINT}

It is unusual not to find some reference to the reconstructive surgery of the knee on opening an orthopaedic journal. Most of the articles add to our knowledge of the subject but the information can confuse us, particularly when pathological states are described. For example, the term "anteromedial instability" has come to mean a situation in which the pivot of rotatory movement is shifted laterally, and consequently the medial tibial condyle can be displaced forwards and rotated laterally. There is no doubt that the authors know what they mean but readers are confused by the apparent mixture of medials and laterals and pivots.

If terminology of pathological states can be clarified problems still remain, particularly because physical signs may be interpreted wrongly from an inadequate knowledge of pathological anatomy. We all know that the normal knee joint will flex and extend and that in full extension there is no rotatory movement. As soon as any flexion is permitted rotatory movement can start around a more or less central pivot. This movement is essential to the function of the knee. In ligament injuries we are concerned with the abnormal movements: these produce a joint subluxation or a joint dislocation and should be so described. The whole tibia may subluxate pathologically forwards or backwards, or into valgus or varus, or one condyle alone may move abnormally in which case the subluxation must be a rotatory one.

The concept of simple terminology has been suggested by Apley. Instability of the knee is commonly of a rotatory type. There are two types of rotatory instability: the type caused by a ligament injury which is a rotatory instability with subluxation, and the type caused by a torn meniscus or a loose body which is a rotatory instability without subluxation. The loose term "anteromedial rotatory instability" covers these two different conditions. Therefore when we are talking about instability from ligament injuries Apley suggests that we describe the pathological movement by the subluxation we observe. Anteromedial rotatory instability due to damaged medial ligament complex is renamed anteromedial subluxation. This is a correct description of what is happening. The true anterior draw sign is an example of the anterior subluxation, and the posterior draw is a posterior subluxation. Divided lateral structures cause a varus subluxation.

The exact physical signs produced by ligament injuries singly or in combination can be determined by examination of the knees of amputation specimens. Anteromedial subluxation is produced by divided medial structures. If the anterior cruciate ligament is also divided the anteromedial subluxation is increased. When the anterior cruciate ligament is divided in isolation the only abnormal movement is an anterolateral subluxation. The amount of subluxation is very variable. It is marked only if the posterolateral capsule is also divided. It must be emphasised that there is no pure anterior subluxation, which can be produced only by a combination of division of medial structures and the anterior cruciate ligament. These three types of late subluxation, namely anteromedial, anterolateral and anterior can be improved by surgical repair. They must be carefully distinguished because the repair procedures are quite different for each instability.

Late posterior subluxation of all types is quite a different problem because the available methods of repair at present are very poor. The treatment is prevention by accurate diagnosis at time of injury when primary repair can give a good result.

It must be emphasised strongly that before any reconstruction the exact instability must be defined. A detailed clinical description of the turning movement 